Abbas Abdollahi $\quad$ ORCID iD: 0000-0002-8346-5043

\title{
Academic Hardiness as a Mediator for the Relationship Between School Belonging and Academic Stress
}

\author{
Abbas Abdollahi \\ Alzahra University \\ Sana Panahipour \\ Kharazmi University \\ Mahnaz Akhavan Tafti \\ Alzahra University \\ Kelly A. Allen \\ Monash University \\ Author Note
}

Abbas Abdollahi, Department of Counseling, Faculty of Education and Psychology, Alzahra University.

Sana Panahipour, Department of Educational Psychology, Kharazmi University.

This is the author manuscript accepted for publication and undergone full peer review but has not been through the copyediting, typesetting, pagination and proofreading process, which may lead to differences between this version and the Version of Record. Please cite this article as doi: 10.1002/pits.22339.

This article is protected by copyright. All rights reserved. 
Mahnaz Akhavan Tafti, Department of Educational Psychology, Faculty of Education and Psychology, Alzahra University.

Kelly A. Allen, Educational Psychology and Inclusive Education, Faculty of Education, Monash University.

Correspondence concerning this article should be addressed to Abbas Abdollahi, Tel: 00989126585744, email: a.abdollahi@alzahra.ac.ir

\begin{abstract}
Academic stress is a commonly reported affective state by high school students that can be accompanied by unwanted and unhelpful short- and long-term implications including a low sense of school belonging. Understanding how academic stress may be alleviated or managed by students is an essential consideration for all schools concerned with student wellbeing. This study aimed to examine the relationship between academic stress and sense of school belonging, as well the mediation effect of academic hardiness. Four hundred and five high-school students from six schools in Tehran, Iran were recruited in the study. Data analyses with Structural Equation Modeling revealed that a sense of belonging to school $(\beta=-.38, p<.01)$ and academic hardiness $(\beta=-.40, p<.01)$ were significant predictors of academic stress. Bootstrapping analysis showed that academic hardiness acted as a mediator between a sense of belonging to school and academic stress. The findings elucidate the underlying mechanism in how low school belonging may lead to academic stress in high-school students. Creating a culture of school
\end{abstract}

This article is protected by copyright. All rights reserved. 
belonging and teaching and supporting skills related to academic hardiness should be key considerations for all schools seeking to reduce academic stress experienced by their students.

Keyword: school belonging, academic stress, academic hardiness, students, mediator Academic hardiness as a mediator for the relationship between school belonging and academic stress

Academic stress has been found to have a significant and adverse effect on all students, but particularly those in adolescence (Jung \& Kim, 2017). Academic stress in this developmental period can have a profoundly negative effect on physical and psychological health (Singh \& Upadhyay, 2010); learning (Dahlin, Joneborg, \& Runeson, 2005); motivation (Huan, See, Ang, \& Har, 2008); wellbeing; sleep quality (Wunsch, Kasten, \& Fuchs, 2017); and mental health ( i.e., leading to anxiety and depression [Dyrbye, Thomas, \& Shanafelt, 2006; Putwain, 2007]).

Studies have shown that most students experience high levels of academic stress (Choi, Lee, Yoo, \& Ko, 2019; Rajoo, Karam, \& Abdul Aziz, 2019). Academic stress occurs when academic demands exceed a student's perceived ability to cope (Wilks, 2008). Sources of academic stress can stem from self-imposed pressure to perform academically, perceived parental pressures towards academic achievement (Lee, Choi, \& Kong, 2011; Wunsch et al., 2017), and cultural expectations to achieve at school (AKGUN \& CIARROCHI, 2003). In Iran, prerequisites to attend university involve passing the national entrance exam (Konkoor) and achieving a high grade point average (GPA) during high school (Arani, Kakia, \& Karimi, 2012). Only 15\% of students are

This article is protected by copyright. All rights reserved. 
accepted into public universities, therefore there is a high degree of competition which may lead to Iranian students in particular to experience high levels of academic stress.

Studies have shown that school belonging can develop positive emotional wellbeing, motivation for academic success, and can secure students from the risks of academic stress (Abdollahi \& Noltemeyer, 2018; Allen, Vella-Brodrick, \& Waters, 2017; Tong, Reynolds, Lee, \& Liu, 2019). A sense of belonging to school is defined as a student's perception about feeling accepted, valued, and cared for within their school environment (Goodenow \& Grady, 1993). School belonging, as a field of research, faces a number of challenges due to the variety of operational definitions that exist. For example, in the academic literature, a sense of school belonging has been described as interest and engagement in school (Wentzel, 1994), participation in school activities (Roeser, Midgley, \& Urdan, 1996), and related to the quality of students' interpersonal interactions (Booker, 2006). Other scholars have used definitions of school belonging that consider a student's sense of belonging to school as a multi-dimensional construct (e.g., Goodenow \& Grady, 1993; Allen et al., 2018). While various terms and definitions exist to describe school belonging, Goodenow and Grady’s (1993) definition is used widely (Allen, Kern, Vella-Brodrick, Hattie, \& Waters, 2018; Hernández, Robins, Widaman, \& Conger, 2016; Wentzel, Russell, \& Baker, 2016; Won, Wolters, \& Mueller, 2018) and operationalised through the Psychological Sense of School Membership (PSSM) scale (Goodenow, 1993).

The belongingness hypothesis (Baumeister \& Leary, 1995) and Maslow’s Hierarchy of Needs (Maslow, 1943) emphasize the importance of interpersonal relationships and belongingness to groups for positive psychological outcomes.

This article is protected by copyright. All rights reserved. 
According to these theories, it is conceivable that positive interactions with classmates and teachers and a sense of belongingness to school could reduce the experience of academic stress. Conversely, a poor sense of affiliation to school and weak relationships with peers and teachers may lead to academic stress (Allen et al., 2018).

As a psychological construct, academic hardiness may mediate the relationship between academic stress and school belonging. It is comprised of three components: Commitment, challenge, and control. Commitment involves the motivation and drive to achieve academically, despite competing demands that may exist (e.g., negative peer pressure, responsibilities within the family). Challenge involves perceiving academic difficulties as a normal and common aspect of the educational experience that may lead to further opportunities for personal growth and success. Control involves self-awareness over one's own ability to achieve positive academic outcomes and use emotional selfregulation and coping skills to manage academic stress (Benishek, Feldman, Shipon, Mecham, \& Lopez, 2005).

Studies have shown that a sense of belonging to school (Allen, Kern, VellaBrodrick, \& Waters, 2017; Ho, Schweitzer, \& Khawaja, 2017) and academic hardiness (Abdollahi, Carlbring, Vaez, \& Ghahfarokhi, 2018; Hystad, Eid, Laberg, Johnsen, \& Bartone, 2009) have a significant relationship with academic stress. Studies have found that academic hardiness has a significantly positive association with a sense of belonging to school (Abdollahi \& Noltemeyer, 2018; Høigaard, Kovač, Øverby, \& Haugen, 2015) and a significantly negative association with academic stress (Hystad et al., 2009). It is conceivable that students with high levels of a sense of belonging to school are more likely to be motivated to learn and do well at school, perceive academic challenges as 
opportunities for growth, and employ effective strategies for emotional self-regulation to mitigate maladaptive outcomes (Abdollahi \& Noltemeyer, 2018; Allen et al., 2017; Allen et al., 2018; Karimi \& Venkatesan, 2009). Therefore, students with these characteristics are less likely to experience academic stress. In order to build on the existing empirical literature from Iran and other countries (e.g., Abdollahi et al., 2018; Abdollahi \& Noltemeyer, 2018; Allen et al., 2018), the purpose of this study was to examine the relationships between school belonging, academic hardiness and academic stress. A second aim of this study was to test the mediating role of academic hardiness in the link between a sense of belonging to school and academic stress. Understanding the relationship between these variables is important for educators, clinicians, school leaders and policy makers concerned with improving educational outcomes for young people in Iran and elsewhere around the world.

\section{Method}

Participants

A total of 405 students from Grades 9 to 12 (235 females and 170 males) from six high schools in Tehran participated in the present study. Participants' ages ranged from 15 to 21 years old $(M=17 \pm 1.98)$. The number of students in each year level were similar: 100 students were in the first year of high school, 104 students in the second year, 111 students were in the third year, and 90 were in the fourth year.

\section{Measures}

Academic hardiness scale (AHS). The AHS is a self-reporting measure that has 18 items. It evaluates academic hardiness, which includes the three subscales of control, commitment, and challenge. Each subscale includes six items, and the total score is 
computed by summing the item scores (Benishek \& Lopez, 2001). Possible responses are based on a four-point Likert scale from 1 (completely false) to 4 (completely true). The marks range from 18 to 72, with greater scores indicating greater levels of academic hardiness. The Iranian translation of the AHS (Abdollahi \& Noltemeyer, 2018) was used in this study, and it revealed an acceptable internal consistency. The internal consistency score for the AHS was .89 for the present study.

Academic expectations stress inventory (AESI). The AESI is a self-reporting measure with nine items that evaluate academic stress, including a student's own expectations, his or her teacher's expectations, and his or her parent's expectations. The responses are based on a five-point Likert scale that ranges from 1 (never true) to 5 (almost always true). The overall score of AESI is made by summing item scores. The scores range from 9 to 45. Larger scores indicate greater academic stress (Ang \& Huan, 2006). The Iranian translation of the AESI (Habibi, 2015) was used in this study and it revealed acceptable reliability and internal consistency $(\alpha: .88)$.

School belonging scale (SBS). The SBS is a self-reporting measure, which has 60 items that evaluates a sense of belonging at school. It includes six subscales of connecting: with teachers, with parents/caregivers, with peers, with oneself, with learning, and with professional help and support. Each subscale includes ten items, and the final score is computed by summing the scores of six subscales (Allen \& Kern, 2018). The answers are based on a three-point Likert scale from 0 (not at all) to 2 (very much). The overall score of SBS is made by totaling responses. The marks range from 0 to 120 ; the greater the score, the higher the level of a sense of belonging to school (Allen \&

This article is protected by copyright. All rights reserved. 
Kern, 2018). For the present study, the measure had good reliability and internal consistency ( $\alpha$ : .85).

\section{Questionnaire Translation}

The school belonging scale was translated from English to Persian, then backtranslated into English (Brislin, 1980). Three experts compared the three versions of the questionnaire, in order to ensure the accuracy of items for each version.

\section{Procedure}

Prior to data collection, human ethics to conduct the study was approved by the Alzahra University's review committee and permission was obtained from the Ministry of Education. Multistage random cluster sampling of 32 schools in District 11 of Tehran took place yielding six schools for the present study (three schools for girls and three schools for boys). Students were grouped into four categories based on their year level (first year to the fourth year of high school). Classes were randomly selected from each school to collect data.

Prior to students completing questionnaires, the researchers explained the goals of the study and requested their signed and informed consent. Students were advised that participation in the study was not compulsory, and that they could withdraw at any time. The questionnaires were completed by students in one session, and the average time for completing the questionnaires was about 30 minutes. Of the 420 questionnaires distributed, 15 were removed due to incomplete responses or outliers. 


\section{Data Analysis}

Statistical Package for Social Science (SPSS 24) was employed for the descriptive analysis of the studied variables. Analysis of Moment Structures (AMOS23) software was also used to test the research hypotheses of the study, which included a measurement model, structural model, and mediation model (Arbuckle, 2006).

\section{Results}

Primary Analyses

Prior to running the data analyses, missing data was computed, and the values for items less than $2 \%$ was addressed by the regression method. Data was considered as being an outlier when the $\mathrm{Z}$ score was outside the value of \pm 3.29 (Tabachnick \& Fidell, 2013). Results showed the $Z$ scores did not exceed \pm 3.29 . To evaluate the distribution of data, the values of the skewness (-1.81 to 0.98$)$ and kurtosis (-1.16 to 1.73$)$ of data did not exceed thresholds of \pm 2 (Tabachnick \& Fidell, 2013). Therefore, the variables were considered to be normally distributed.

\section{Descriptive Statistics}

Table 1 lists the simple correlation between the studied variables and the mean, standard deviations, and actual range. The correlation analysis showed that a sense of belonging to school negatively correlated with academic stress $(r=-.42, p<.01)$, but positively correlated with academic hardiness $(\mathrm{r}=.39, p<.01)$. Conversely, academic hardiness was negatively correlated with academic stress ( $\mathrm{r}=-.45, p<.01)$.

This article is protected by copyright. All rights reserved. 


\section{Measurement Model for Each Scale}

A confirmatory factor analysis was computed on a sense of belonging to school (60 items), academic hardiness (18 items), and academic stress (9 items). The results indicated that the factor loadings of the items ranged from .50 to .92 , which were greater than the cut-off score of .5 (Kline, 2005). Therefore, the scales were deemed acceptable in the present study. The fit indices were selected as the criteria for a model of good fit: comparative fit index $(\mathrm{CFI})>$.90; Tucker-Lewis index $(\mathrm{TLI})>.90$; Goodness of Fit Index (GFI) > .90; Root Mean Squared Error of Approximation (RMSEA) < .08; and CMIN/df < 5 (Byrne, 2013). The results of the measurement model showed that each scale had an acceptable fit (see Table 2).

\section{Measurement Model for All Scales}

This study built a measurement model comprised of three latent variables: a sense of belonging to school, academic hardiness, and academic stress. The fit indices indicated that the data fit the model well: CMIN/df $=4.11, p<0.01$, CFI $=.91$, GFI $=.90$, TLI $=.91$, and RMSEA $=.07$. This finding showed that the latent variables could be wellrepresented by their observed items.

\section{Structural Regression Model}

The results of the structural regression model demonstrated adequate fit (CMIN/df $=4.67, p<0.01, \mathrm{CFI}=.90, \mathrm{GFI}=.90, \mathrm{TLI}=.90$, and $\mathrm{RMSEA}=.08)$. Results showed that a sense of belonging to school $(\beta=-.38, p<.01)$ and academic hardiness $(\beta=-.40, p<.01)$ negatively predicted academic stress. Findings indicated that a sense of belonging to school was positively associated with academic hardiness $(\beta=.36, p<.01)$. School belonging and academic hardiness explained $46 \%$ of the variance in the academic stress.

This article is protected by copyright. All rights reserved. 


\section{Mediation Analysis of Academic Hardiness}

A bootstrapping method involved 5,000 resamples and an alpha set at .05 via a 95\% bias-corrected confidence interval (CI). CI was employed to test the statistical significance of the indirect effect of a sense of belonging to school on academic stress through academic hardiness. A mediating effect is confirmed when zero is outside of CI (Preacher \& Hayes, 2008). Furthermore, if the significance level from the association between a predicting variable and an outcome variable is significant at the full mediation model, it indicates a partial mediation (Baron \& Kenny, 1986).

The results showed that the relationship between a sense of belonging to school and academic stress was significant in the direct model $(\beta=-.38, p<.01)$. When academic hardiness as a mediator was added to the full mediation model, the beta coefficient from the relationship between a sense of belonging to school and academic stress decreased ( $\beta=-.16, p<.01)$. However, it was still significant (see Table 3 ). Thus, academic hardiness partially mediated this path.

\section{Discussion}

The results of the current study demonstrated a negative relationship between a sense of belonging to school and academic stress, which is in line with previous studies (Allen et al., 2018; Liu \& Lu, 2012; Sun, Dunne, Hou, \& Xu, 2013). It seems reasonable to assume that stress of any kind may hinder interpersonal relationships. According to the belongingness hypothesis (Baumeister \& Leary, 1995), at the core of belongingness is the need to connect with others and develop secure relationships. Stress, mental illness, emotional instability and psychological stress can negatively effect relationships and their 
presence can have a negative and reciprocal relationship with a sense of school belonging as reported previously (Allen et al., 2018; McMahon, Wernsman, \& Rose, 2009).

Students with high levels of a sense of belonging at school are more likely to have effective interpersonal interactions with their peers and teachers, and they are more likely to receive increased social support as a result. Positive interpersonal interactions and social support from others could provide effective solutions for students who face academic difficulties, which could reduce their academic stress (Cohen, Gottlieb, \& Underwood, 2000; Wang \& Eccles, 2012). For example, teacher support (which includes personal and emotional support as well as academic support) may contribute to lower academic stress (Allen et al., 2018). Thus, school leaders should consider various mechanisms for creating a culture of school belonging to alleviate academic stress in students (Allen \& Kern, 2019).

The results of the present study also showed an inverse relationship between academic hardiness and academic stress, which is corroborated by previous studies (Hystad et al., 2009; Spiridon \& Evangelia, 2015). Students with high levels of academic hardiness are more likely to commit to school and educational activities, react positively to academic challenges, effectively modulate their own emotions to overcome academic difficulties, and use adaptive coping strategies to deal with academic failures (Abdollahi et al., 2018; Spiridon \& Evangelia, 2015). Therefore, the results of the present study provide further evidence for the need for schools to deliver social and emotional learning opportunities for students to strengthen their competencies in academic hardiness, resilience and coping that may also in turn reduce their academic stress.

This article is protected by copyright. All rights reserved. 
The results of this study showed that academic hardiness may explain why students with a high sense of school belonging are more likely to show lower levels of academic stress. The mediation analysis indicated that greater levels of academic hardiness observed in students with a significant sense of belonging to school explained their lower levels of academic stress, which indicates that academic hardiness plays a key role in understanding the school belonging academic stress relationship (Abdollahi \& Noltemeyer, 2018; Høigaard et al., 2015). A sense of school belonging has been found to have a significant and positive association with academic motivation, self-regulation, and positive attitudes towards learning (Allen et al., 2018; Hystad, Eid, Laberg, Johnsen, \& Bartone, 2009; Abdollahi \& Noltemeyer, 2018). It is feasible to assume that these variables also relate to academic hardiness and therefore, students who experience a strong sense of school belonging and also demonstrate academic hardiness may have less academic stress. This finding highlights the importance of both individual characteristics and environmental factors in reducing academic stress in students.

\section{Implications of Study}

School psychologists, clinicians, school leaders and teachers should be aware of the significant associations between a sense of belonging to school, academic hardiness, and academic stress in students. Assessing a student's sense of belonging to school and their academic hardiness may provide useful data for devising programs, interventions and strategies aimed at reducing academic stress (e.g., see Allen \& Kern, 2017 and Allen \& Kern, 2019).

The findings of this study extend the empirical literature and highlight the mediating role of academic hardiness in the link between a sense of belonging to school 
and academic stress. Although this study is not intended to be an intervention, academic hardiness could be considered to be a core social and emotional competency to be fostered in students as a way to address academic stress and levels of school belonging. Academic hardiness training in schools may enable increased student engagement, improved positive perceptions about school in general, and allow students to pursue goals for the future and view academic opportunities as valuable, meaningful, or noteworthy rather than stressful or overwhelming (Sheard, 2009). However, research in this area is limited and there is a critical need for future research to investigate how academic hardiness could be best implemented and supported in schools.

\section{Research Limitations}

The data for this study was collected from high school students in one region in Tehran. Therefore, caution should be taken with interpreting the results based on the limits of generalizability to other contexts and populations. Future research could examine the proposed model in other populations and geographical regions. Another limitation is concerned with the self-report surveys and the inability to control social desirability with this method. Future research could overcome this limitation by considering objective methods (e.g., observations and interviews) to evaluate the relationships between variables. Another limitation relates to the use of cross-sectional surveys and the inability to assess the developmental aspects of the modeled relationships. Longitudinal designs that address this issue should be considered in subsequent research.

This article is protected by copyright. All rights reserved. 


\section{Conclusions}

Based on the findings of this study, a sense of belonging to school and academic hardiness are able to predict academic stress in students. The findings of this study suggest that academic hardiness mediates the relationship between school belonging and academic stress in Iranian high schools.

\section{References}

Abdollahi, A., Carlbring, P., Vaez, E., \& Ghahfarokhi, S. A. (2018). Perfectionism and Test Anxiety among High-School Students: the Moderating Role of Academic Hardiness. Current Psychology, 37(3), 632-639. https://doi.org/10.1007/s12144016-9550-z

Abdollahi, A., \& Noltemeyer, A. (2018). Academic hardiness: Mediator between sense of belonging to school and academic achievement? Journal of Educational Research, 111(3), 345-351. https://doi.org/10.1080/00220671.2016.1261075

AKGUN, S., \& CIARROCHI, J. (2003). Learned Resourcefulness Moderates the Relationship Between Academic Stress and Academic Performance. Educational Psychology, 23(3), 287-294. https://doi.org/10.1080/0144341032000060129

Allen, K.-A., Kern, M. L., Vella-Brodrick, D., \& Waters, L. (2017). School Values: A Comparison of Academic Motivation, Mental Health Promotion, and School Belonging With Student Achievement. The Educational and Developmental Psychologist, 34(1), 31-47. https://doi.org/10.1017/edp.2017.5

Allen, K., Kern, M. L., Vella-Brodrick, D., Hattie, J., \& Waters, L. (2018). What schools 
need to know about fostering school belonging: A meta-analysis. Springer.

Allen, K., Vella-Brodrick, D., \& Waters, L. (2017). School belonging and the role of social and emotional competencies in fostering an adolescent's sense of connectedness to their school. In Social and emotional learning in Australia and the Asia-Pacific (pp. 83-99). Springer.

Ang, R. P., \& Huan, V. S. (2006). Academic Expectations Stress Inventory. Educational and Psychological Measurement, 66(3), 522-539. https://doi.org/10.1177/0013164405282461

Arani, A. M., Kakia, M. L., \& Karimi, M. V. (2012). Assessment in education in Iran. Assessment. Retrieved from http://www.nwu.ac.za/sites/www.nwu.ac.za/files/files/psaeduc/New_Folder_1/3_Assessment in education in Iran.pdf

Arbuckle, J. L. (2006). Amos (version 20)[computer program]. Chicago: IBM, SPSS.

Baron, R. M., \& Kenny, D. A. (1986). The moderator-mediator variable distinction in social psychological research: Conceptual, strategic, and statistical considerations. Journal of Personality and Social Psychology, 51(6), 1173. https://doi.org/10.1037/0022-3514.51.6.1173

Baumeister, R. F., \& Leary, M. R. (1995). The need to belong: desire for interpersonal attachments as a fundamental human motivation. Psychological Bulletin, 117(3), 497. Retrieved from https://psycnet.apa.org/buy/1995-29052-001

This article is protected by copyright. All rights reserved. 
Benishek, L. A., Feldman, J. M., Shipon, R. W., Mecham, S. D., \& Lopez, F. G. (2005). Development and evaluation of the revised academic hardiness scale. Journal of Career Assessment, 13(1), 59-76. https://doi.org/10.1177/1069072704270274

Benishek, L. A., \& Lopez, F. G. (2001). Development and initial validation of a measure of academic hardiness. Journal of Career Assessment, 9(4), 333-352. https://doi.org/10.1177/106907270100900402

Booker, K. C. (2006). School belonging and the African American adolescent: What do we know and where should we go? The High School Journal, 89(4), 1-7. https://doi.org/https://www.jstor.org/stable/40364222

Brislin, R. W. (1980). Translation and content analysis of oral and written material. Handbook of Cross-Cultural Psychology, 2(2), 389-444. Retrieved from https://ci.nii.ac.jp/naid/10030056788/

Byrne, B. M. (2013). Structural equation modeling with Mplus: Basic concepts, applications, and programming. Routledge: Taylor\&Francis.

Choi, C., Lee, J., Yoo, M. S., \& Ko, E. (2019). South Korean children’s academic achievement and subjective well-being: The mediation of academic stress and the moderation of perceived fairness of parents and teachers. Children and Youth Services Review, 100, 22-30. https://doi.org/10.1016/j.childyouth.2019.02.004

Cohen, S., Gottlieb, B. H., \& Underwood, L. G. (2000).’Social relationships and Health'in Social support measurement and intervention. In A Guide for Health and Social Scientists. Oxford University Press New York.

This article is protected by copyright. All rights reserved. 
Dahlin, M., Joneborg, N., \& Runeson, B. (2005). Stress and depression among medical students: a cross-sectional study. Medical Education, 39(6), 594-604. https://doi.org/10.1111/j.1365-2929.2005.02176.x

Dyrbye, L. N., Thomas, M. R., \& Shanafelt, T. D. (2006). Systematic review of depression, anxiety, and other indicators of psychological distress among US and Canadian medical students. Academic Medicine, 81(4), 354-373. Retrieved from https://journals.lww.com/academicmedicine/Fulltext/2006/04000/Decreasing_GME _Training_Stress_to_Foster.9.aspx

Goodenow, C., \& Grady, K. E. (1993). The relationship of school belonging and friends’ values to academic motivation among urban adolescent students. The Journal of Experimental Education, 62(1), 60-71. https://doi.org/10.1080/00220973.1993.9943831

Habibi, M. (2015). The effect of cognitive-behavioral stress management on decreasing academic expectation stress of parents: A case of first grade high school students. Journal of School Psychology, 2(14), 22-38. Retrieved from https://www.sid.ir/En/Journal/ViewPaper.aspx?ID=519256

Hernández, M. M., Robins, R. W., Widaman, K. F., \& Conger, R. D. (2016). School Belonging, Generational Status, and Socioeconomic Effects on Mexican-Origin Children’s Later Academic Competence and Expectations. Journal of Research on Adolescence, 26(2), 241-256. https://doi.org/10.1111/jora.12188

Ho, N. K. N., Schweitzer, R. D., \& Khawaja, N. G. (2017). Academic Achievement

This article is protected by copyright. All rights reserved. 
Among Recently Arrived Chinese Adolescent Migrants: The Role of Social Support, School Belonging, and Acculturative Stress. Journal of Psychologists and Counsellors in Schools, 27(1), 24-36. https://doi.org/10.1017/jgc.2016.4

Høigaard, R., Kovač, V. B., Øverby, N. C., \& Haugen, T. (2015). Academic self-efficacy mediates the effects of school psychological climate on academic achievement. School Psychology Quarterly, 30(1), 64.

Huan, V. S., See, Y. L., Ang, R. P., \& Har, C. W. (2008). The impact of adolescent concerns on their academic stress. Educational Review, 60(2), 169-178. https://doi.org/10.1080/00131910801934045

Hystad, S. W., Eid, J., Laberg, J. C., Johnsen, B. H., \& Bartone, P. T. (2009). Academic Stress and Health: Exploring the Moderating Role of Personality Hardiness. Scandinavian Journal of Educational Research, 53(5), 421-429. https://doi.org/10.1080/00313830903180349

Jung, I.-K., \& Kim, J.-H. (2017). Effects of Academic Stress and Academic Burnout on Smartphone Addiction in Junior High School Students. The Korean Journal of Community Living Science, 28(2), 289-300. https://doi.org/10.7856/kjcls.2017.28.2.289

Karimi, A., \& Venkatesan, S. (2009). Mathematics Anxiety, Mathematics Performance and Academic Hardiness in High School Students. International Journal of Educational Sciences, 1(1), 33-37. https://doi.org/10.1080/09751122.2009.11889973

This article is protected by copyright. All rights reserved. 
Kline, R. B. (2005). Principles and Practice of Structural Equation Modeling (3rd edn). In New York. Retrieved from http://books.google.com.my/

Lee, K. Y., Choi, S. C., \& Kong, J. S. (2011). The effects of parents-children dysfunctional communication and academic stress on adolescents' suicide ideationfocusing on the mediating effects of depression and gender differences. Korean Journal of Youth Studies, 18(5), 83-108.

Liu, Y., \& Lu, Z. (2012). Chinese High School Students’ Academic Stress and Depressive Symptoms: Gender and School Climate as Moderators. Stress and Health, 28(4), 340-346. https://doi.org/10.1002/smi.2418

Maslow, A. H. (1943). A theory of human motivation. Psychological Review, 50(4), 370396. https://doi.org/10.1037/h0054346

Preacher, K. J., \& Hayes, A. F. (2008). Asymptotic and resampling strategies for assessing and comparing indirect effects in multiple mediator models. Behavior Research Methods, 40(3), 879-891. https://doi.org/10.3758/BRM.40.3.879

Putwain, D. (2007). Researching academic stress and anxiety in students: some methodological considerations. British Educational Research Journal, 33(2), 207219. https://doi.org/10.1080/01411920701208258

Rajoo, K. S., Karam, D. S., \& Abdul Aziz, N. A. (2019). Developing an effective forest therapy program to manage academic stress in conservative societies: A multidisciplinary approach. Urban Forestry \& Urban Greening, 43, 126353. https://doi.org/10.1016/j.ufug.2019.05.015

This article is protected by copyright. All rights reserved. 
Roeser, R. W., Midgley, C., \& Urdan, T. C. (1996). Perceptions of the school psychological environment and early adolescents’ psychological and behavioral functioning in school: The mediating role of goals and belonging. Journal of Educational Psychology, 88(3), 408.

Sheard, M. (2009). Hardiness commitment, gender, and age differentiate university academic performance. British Journal of Educational Psychology, 79(1), 189-204. https://doi.org/10.1348/000709908X304406

Singh, A., \& Upadhyay, A. (2010). Academic stress and psychological health: An indigenous approach. Social Science International, 26(1), 87-96. https://doi.org/https://doi.org/10.1037/0022-0663.88.3.408

Spiridon, K., \& Evangelia, K. (2015). Exploring relationships between academic hardiness, academic stressors and achievement in university undergraduates. NHSA Dialog, 1(1), 53-73. Retrieved from https://journals.uncc.edu/jaepr/article/view/317

Sun, J., Dunne, M. P., Hou, X., \& Xu, A. (2013). Educational stress among Chinese adolescents: individual, family, school and peer influences. Educational Review, 65(3), 284-302.

Tabachnick, B. G., \& Fidell, L. S. (2013). Using Multivariate Statistics, 6th International edition (cover) edn. Sage Publications, Thousand Oaks.

Tong, L., Reynolds, K., Lee, E., \& Liu, Y. (2019). School relational climate, social identity, and student well-being: new evidence from China on student depression and stress levels. School Mental Health, 11(3), 509-521.

This article is protected by copyright. All rights reserved. 
https://doi.org/https://doi.org/10.1007/s12310-018-9293-0

Wang, M., \& Eccles, J. S. (2012). Social support matters: Longitudinal effects of social support on three dimensions of school engagement from middle to high school. Child Development, 83(3), 877-895. https://doi.org/https://doi.org/10.1111/j.14678624.2012.01745.x

Wentzel, K. R. (1994). Relations of social goal pursuit to social acceptance, classroom behavior, and perceived social support. Journal of Educational Psychology, 86(2), 173. https://doi.org/10.1037/0022-0663.86.2.173

Wentzel, K. R., Russell, S., \& Baker, S. (2016). Emotional support and expectations from parents, teachers, and peers predict adolescent competence at school. Journal of Educational Psychology, 108(2), 242. https://doi.org/10.1037/edu0000049

Won, S., Wolters, C. A., \& Mueller, S. A. (2018). Sense of belonging and self-regulated learning: Testing achievement goals as mediators. The Journal of Experimental Education, 86(3), 402-418. https://doi.org/10.1080/00220973.2016.1277337

Wunsch, K., Kasten, N., \& Fuchs, R. (2017). The effect of physical activity on sleep quality, well-being, and affect in academic stress periods. Nature and Science of Sleep, 9, 117. https://doi.org/10.2147/NSS.S132078

This article is protected by copyright. All rights reserved. 
Table 1. The mean, standard deviations, actual range, and correlation among study variables

\begin{tabular}{llll}
\hline Variables & 1 & 2 & 3 \\
\hline Mean & 52.75 & 41.12 & 19.81 \\
Standard deviation & & & \\
Actual range & 9.11 & 8.41 & 6.11 \\
(1) Sense of belonging to school & $30-101$ & $18-70$ & $9-43$ \\
(2) Academic hardiness & 1 & & \\
(3) Academic stress & & & \\
\hline
\end{tabular}

Note. ${ }^{* *} p<.01$

Table 2. Measurement Model for each scale

\begin{tabular}{llllll}
\hline Measurement Model & CMIN/df & RMSEA & CFI & GFI & TLI \\
\hline Sense of belonging to school & 4.01 & .07 & .91 & .92 & .90 \\
Academic hardiness & 3.85 & .06 & .92 & .93 & .91 \\
Academic stress & 3.96 & .07 & .94 & .93 & .91
\end{tabular}

This article is protected by copyright. All rights reserved. 
Table 3. Testing mediation of academic hardiness

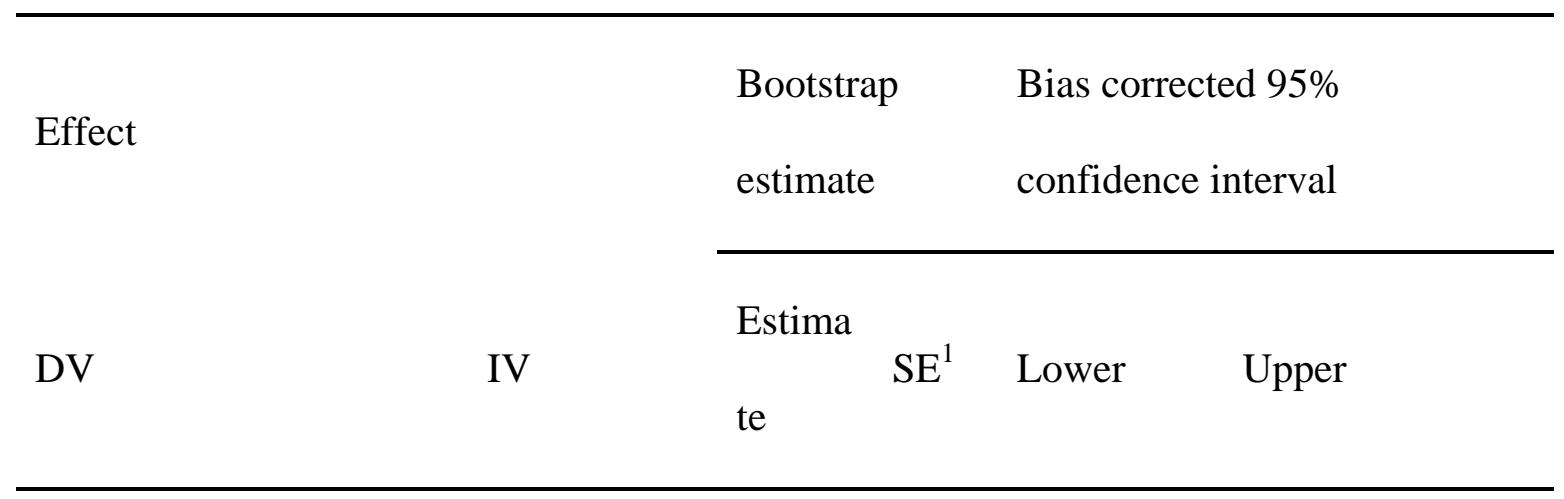

\section{Direct Model}

$\begin{array}{lllllll}\text { Sense of belonging } & < & \text { Academic } & & & & \\ & & & -.38 * * & -.046 & -.43 & -.23 \\ \text { to school } & - & \text { stress } & & & & \end{array}$

\section{Full Mediation Model}

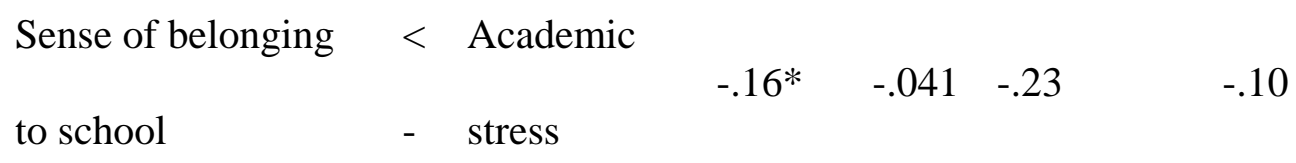

Note: ${ }^{*} p<0.05,{ }^{* *} p<0.01,1$ : Standard Error

This article is protected by copyright. All rights reserved. 


\section{University Library}

\section{- M M N E R VA A gateway to Melbourne's research publications}

Minerva Access is the Institutional Repository of The University of Melbourne

Author/s:

Abdollahi, A;Panahipour, S;Tafti, MA;Allen, KA

Title:

Academic hardiness as a mediator for the relationship between school belonging and academic stress

Date:

2020-01-18

Citation:

Abdollahi, A., Panahipour, S., Tafti, M. A. \& Allen, K. A. (2020). Academic hardiness as a mediator for the relationship between school belonging and academic stress.

PSYCHOLOGY IN THE SCHOOLS, 57 (5), pp.823-832. https://doi.org/10.1002/pits.22339.

Persistent Link:

http://hdl.handle.net/11343/276829 